\title{
CORONAVÍRUS E SUA PROTEASE PRINCIPAL: UMA VISÃO PARA O PLANEJAMENTO DE FÁRMACOS POR DOCAGEM MOLECULAR
}

\author{
CORONAVIRUS AND ITS MAIN PROTEASE: AN INSIGHT FOR DRUGS \\ DESIGN BY MOLECULAR DOCKING
}

\begin{abstract}
${ }^{1}$ Simone Queiroga Brito Gonçalves.
${ }^{1}$ Eloi Alves da Silva Filho.

${ }^{3}$ Osmair Vital de Oliveira.

${ }^{1,2^{*}}$ Arlan da Silva Gonçalves.

${ }^{1}$ Universidade Federal do Espírito Santo - UFES, Campus Goiabeiras. E-mail: simonequeirogabg@gmail.com; eloisilv@gmail.com.

${ }^{2}$ Instituto Federal de Educação, Ciência e Tecnologia do Espírito Santo - IFES, Campus Vila Velha. E-mail: agoncalves@ifes.edu.br.

${ }^{3}$ Instituto Federal de Educação, Ciência e Tecnologia de São Paulo - IFSP, Campus Catanduva. E-mail: osmairvital@gmail.com.
\end{abstract}

Artigo submetido em 29/04/2020, aceito em 06/05/2020 e publicado em 13/06/2020.

Resumo: Muitos vírus precisam que seus grupos sulfidrila sejam reduzidos para que seja permitida sua entrada nas células. O SARS-CoV-2, que pertence à família Coronaviridae, e é o causador da doença coronavírus 2019 ou COVID-19, apresenta em seu capsídeo proteínas ricas em cisteínas, como a principal protease do $\mathrm{CoV}\left(\mathrm{M}^{\mathrm{PRO}}\right)$, que deve estar intacta e ativa, mantendo a atividade viral. Considerando que a $\mathrm{M}^{\mathrm{PRO}}$ constitui um importante alvo molecular para o desenvolvimento de medicamentos antivirais, a motivação deste trabalho foi o estudo estrutural dos possíveis modos de interação entre os fármacos e as cisteínas virais, pela técnica de docagem molecular, para o planejamento racional de novos potenciais inibidores de $\mathrm{M}^{\mathrm{PRO}}$ e de sua virulência.

Palavras-chave: Coronavírus; Protease; Docagem molecular.

Abstract: Many virus need their sulphydryl groups to be reduced in order to be allowed to enter cells. SARS-CoV-2, which belongs to Coronaviridae family, and is responsible for coronavirus disease 2019 or COVID-19, has cysteine-rich proteins in its capsid as the main $\mathrm{CoV}$ protease $\left(\mathrm{M}^{\mathrm{PRO}}\right)$, which must be intact and active maintaining the viral activity. Considering that $\mathrm{M}^{\mathrm{PRO}}$ is an important molecular target for development of antiviral drugs, this work motivation was the structural study of the possible ways of interaction between drugs and viral cysteines by molecular docking technique for design of new potential inhibitors of $\mathrm{M}^{\mathrm{PRO}}$ and its virulence.

Keywords: Coronavirus; Protease; Molecular docking. 


\section{INTRODUÇÃO}

O SARS-CoV-2, surgido em Wuhan (China) é o "novo coronavírus" responsável pela COVID-19 (coronavirus disease). Os casos iniciais da doença tem sido atribuídos à venda de animais vivos em Wuhan, o que sugere uma provável transmissão do vírus a partir destes animais para humanos. O contágio interpessoal ocorre por meio de secreções contaminadas, como gotículas respiratórias, ou do contato com uma superfície contaminada. Essa fácil transmissibilidade, em nível mundial, ocasionou a pandemia global, assim declarada pela Organização Mundial de Saúde (OMS) em 11 de março de 2020 (WHO, 2020), com expressiva morbimortalidade. Até a presente data (23 de abril de 2020), 213 países foram afetados, onde 2.544.792 casos foram confirmados, com 175.694 mortes (https://www.who.int/emergencies/diseases/ novel-coronavirus-2019).

A China foi o primeiro país a adotar o isolamento domiciliar para dezenas de milhões de pessoas, como forma de responder ao surto e tentar conter a disseminação do SARS-CoV-2. Esse vírus apresenta um período de incubação de pelo menos 14 dias. Nos primeiros dias, é indicado a análise por RT-PCR (Reverse Transcriptase Polymerization Chain Reaction), detectando fragmentos do material genético viral (RNA), quando o organismo do paciente ainda não apresenta quantidades importantes e detectáveis de IgG e IgM anti SARS-CoV-2 (janela imunológica). Quanto à soroconversão, Xiang et al (2020) em seus ensaios conseguiram que os anticorpos fossem detectados por ELISA (Enzyme-Linked Immunosorbent Assay) a partir do quarto dia em que os pacientes apresentaram sintomatologia. No entanto, tendo em vista a janela imunológica, a ANVISA o indica a partir do décimo dia. Outras técnicas que analisam a sorologia são imunocromatografia, CLIA (Chemiluminescent Immunoassay) e imunofluorecscência (Xiang et al, 2020; ANVISA, 2020).

De acordo com um estudo recente chinês, cerca de $80 \%$ dos pacientes apresentaram leves sintomas associados à presença do vírus, como tosse seca, cansaço, febre (podendo haver dor de garganta, congestão nasal ou diarréia) e se recuperam da doença sem necessitar de tratamento hospitalar. A taxa de letalidade verificada foi de $2,3 \%$, atingindo $8,0 \%$ de pacientes com idade entre 70 e 79 anos e $14,8 \%$ daqueles com idade superior aos 80 anos (WU \& MCGOOGAN, 2020). Vale ressaltar que o grande número de portadores assintomáticos e a impossibilidade de testar toda a população constituem fatores que subestimam esta estatística, além de dificultar o controle da pandemia.

Em 14 de março de 2020, enquanto a China já apresentava 84.215 casos, a França enfrentou a COVID-19 com 4.420 casos de infectados. Na mesma data, a Itália registrou 20.207 casos, a Espanha 5.497 casos, a Alemanha 3.755 casos, Reino Unido 1.010 casos, EUA com 2.092 casos, Brasil com 119 (SANTÉ PUBLIQUE FRANCE, 2020; WHO, 2020).

Sendo evidente a necessidade emergencial, tanto para tratar pacientes sintomáticos, aumentando a sua sobrevida, como também para diminuir a transmissão viral, entre os medicamentos candidatos ao tratamento com COVID-19, o uso de medicamentos antigos bioativos, já elucidados pela literatura, pode ser uma estratégia interessante, tendo em vista que para que um fármaco chegue às prateleiras de uma farmácia, como medicamento, o tempo médio é de 10 anos e, ao fim deste tempo, informações como perfil de segurança, efeitos colaterais, posologia e interações medicamentosas devem estar bem elucidadas (COLSON et al., 2020).

Uma informação em relação ao coronavírus, que muito pode ser útil para o planejamento de fármacos com grupos farmacofóricos específicos e de interação com os aminoácidos cisteínas (Cys), é o fato 
de este vírus possuir um número considerável de Cys em sua protease principal $\left(\mathrm{M}^{\mathrm{PRO}}\right)$. Além disso, sabe-se que resíduos de Cys são abundantes também no envelope viral do SARS-CoV-2, mantendoo estruturado e conservado, através de pontes dissulfeto, favorecendo a sua interação com células saudáveis e, consequentemente, a transferência do RNA viral para o interior das mesmas (ROWEN \& ROBINS, 2020).

Em março de 2020, as estruturas tridimensionais da $\mathrm{M}^{\mathrm{PRO}}$ do SARS-CoV-2 complexadas com os ligantes "1-[(2 $\{\mathrm{S}\})-2-$ methylmorpholin-4-yl]-2-pyrazol-1-ylethanone", derivado de pirazol e "N-[(5methylisoxazol-3-yl)carbonyl]alanyl-Lvalyl-N 1 - ((1R,2Z)-4-(benzyloxy)-4-oxo1-\{[(3R)-2-oxopyrrolidin-3-yl]methyl $\}$ but-

2-enyl)-L-leucinamide", derivado de leucinamida, determinadas pela técnica de cristalografia e difração de raios- $X$, foram depositadas no servidor Protein Data Bank (https://www.rcsb.org/), pelos códigos $5 r f 9$ e $6 l u 7$.

Tendo-se esta macromolécula como alvo molecular importante para compreender, em nível molecular, sua possível inibição por fármacos já elucidados e conhecidos, a motivação deste trabalho foi o estudo por docagem molecular da interação desta enzima $\mathrm{M}^{\mathrm{PRO}}$ com a azidotimidina (AZT), importante medicamento utilizado para o tratamento da AIDS e, de forma geral, como anti-retroviral (MAZUROV et al., 2010), com a cloroquina e a hidroxicloroquina, pois estudos recentes mostraram que as mesmas possuem atividade contra o SARS-CoV-2 (CORTEGIANI et al., 2020), além da vitamina $\mathrm{D}$, que em um estudo publicado em 2011, mostrou ter atividade antiviral (BEARD et al., 2011). É bom enfatizar que até a presente data não existe vacina e/ou tratamento contra a COVID-19. O tratamento com o uso de plasma de pacientes imunizados não está disponível para atender à demanda. Logo, o isolamento social ainda é a principal estratégia adotada para impedir a contaminação e a disseminação do vírus SARS-CoV-2.

\section{METODOLOGIA}

$\mathrm{M}^{\mathrm{PRO}} \begin{gathered}\text { As estruturas tridimensionais da } \\ \text { do SARS-CoV-2 complexadas, }\end{gathered}$ respectivamente, com derivados do pirazol e da leucinamida, de códigos $5 r f 9$ e 6lu7, foram adquiridas através do servidor Protein Data Bank (https://www.rcsb.org), renderizadas e visualizadas com o programa PyMol (disponível para download em https://pymol.org), a fim de se investigar possíveis sítios de inibição.

Já as estruturas tridimensionais de todos os ligantes utilizados neste trabalho, Figura 1, foram preparadas e otimizadas, utilizando-se a mecânica clássica, com o programa GHEMICAL (HASSINEN \& PERÄKYLÄ, 2001) e o campo de forças TRIPOS 5.2 (SHIH \& CHEN, 1995). Posteriormente, foi verificado o estado de protonação de cada ligante em $\mathrm{pH} 7,4$, utilizando-se $\quad \mathrm{O}$ programa MARVINSKETCH (gratuito e disponível para download em: https://chemaxon.com/products/marvin) e então submetidos a otimizações semiempíricas, utilizando o programa MOPAC 2016 (STEWART, 2007) e o método PM7 (STEWART, 2007), para colocá-los com parâmetros de ligações, ângulos e ângulos de diedros o mais próximo possível de valores experimentais.

Após as otimizações semi-empíricas, as estruturas tridimensionais dos ligantes foram submetidas ao ACPYPE para a adição de cargas AM1-BCC (DA SILVA \& VRANKEN, 2012), onde são gerados arquivos saída com extensão *.mol2, reconhecidos pelo programa de docagem molecular, utilizado neste trabalho que foi o AUTODOCK VINA (TROTT \& OLSON, 2010).

Paralelamente ao preparo dos ligantes, a $\mathrm{M}^{\mathrm{PRO}}$ do SARS-CoV-2 foi separada do inibidor, visualizada e preparada com o pacote AUTODOCK 
TOOLS (MORRIS et al.,2009), onde foram adicionados hidrogênios polares, importantes para a predição de interações inter e intramoleculares por ligações hidrogênio. Em seguida, a região de interação da proteína, tanto com o derivado de pirazol quanto com o derivado de leucinamida, foi considerada para a realização da docagem molecular e envolvida por uma caixa paralelepipedal, com micro-caixas (small grid box) separadas por $0,1 \mathrm{~nm}$, para o cálculo da superfície potencial, necessária para a predição das interações eletrostáticas receptor-ligante. Assim, todos os parâmetros necessários para a realização da docagem molecular foram adicionados em um arquivo-texto (conf.txt), com a seguinte descrição: receptor $=$ SARS-CoV-2.pdbqt; ligand $=$ ligante.pdbqt; center_x $=-19.293$; center_y $=23.141 ;$ center_z $=66.114$; size $\_\mathrm{x}=50 ;$ size $\_\mathrm{y}=52 ;$ size $\_\mathrm{z}=50 ; \mathrm{cpu}=$ 4 ; num modes $=20$. Como a docagem molecular é uma técnica estocástica, todos os cálculos foram executados 20 vezes, com extração dos 20 melhores resultados para cada ligante, totalizando 400 por ligante, perfazendo 2400 confôrmeros. Dos 400 confôrmeros por ligante, foi escolhido o que apresentou menor valor de DG de interação, ou seja, quanto mais negativo, mais favorável a interação receptor-ligante, termodinamicamente (PIETRALONGA et al., 2015). Trata-se basicamente de interações receptor-ligante, no computador, onde $o$ ligante busca por complementariedades eletrostática e de van Der Waals, sendo que o efeito do solvente é tratado implicitamente, através da constante dielétrica, além de uma esfera ou caixa que engloba o sistema de interesse.

Figura 1: Representação 2D dos ligantes utilizados neste trabalho.

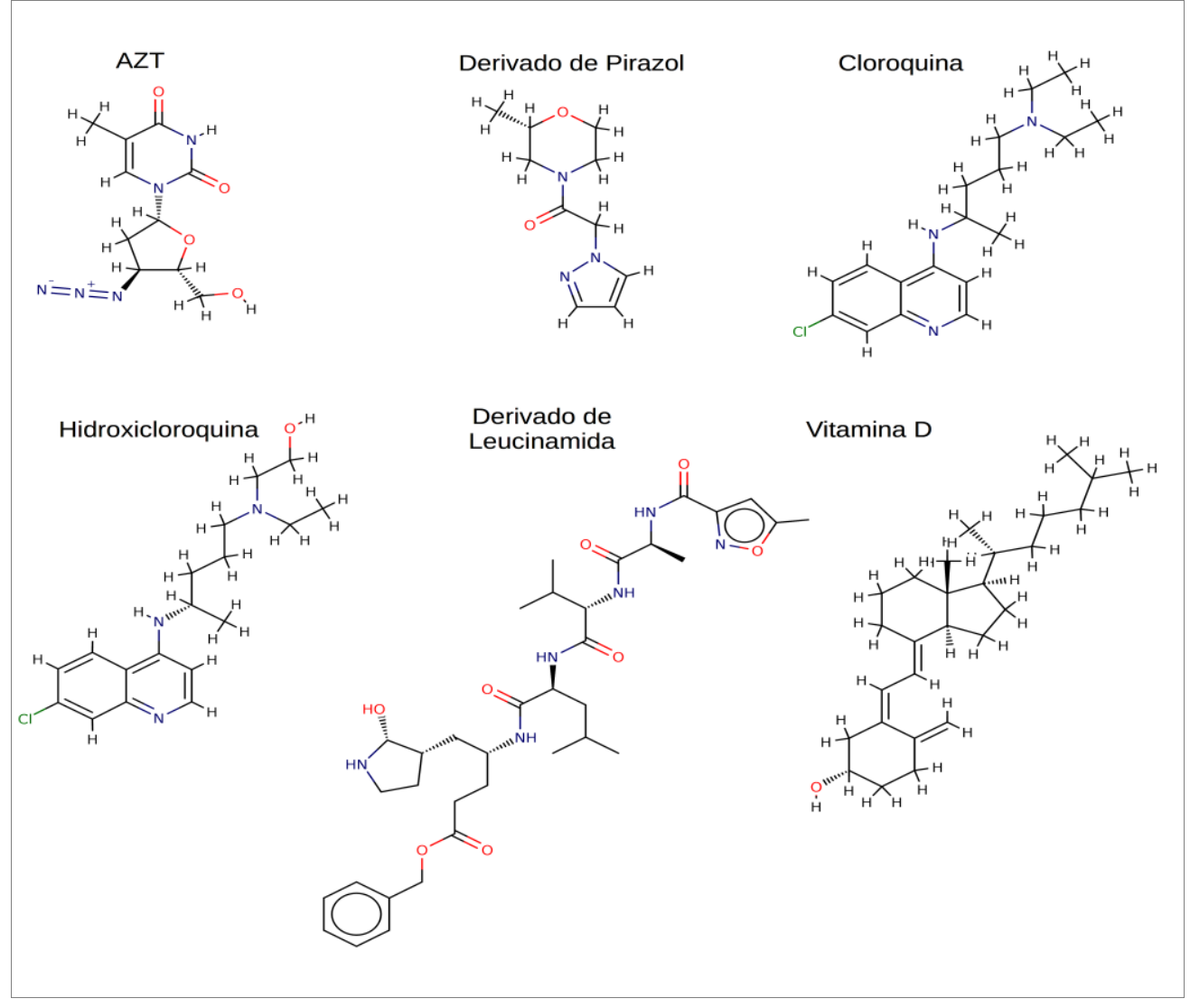




\section{RESULTADOS E DISCUSSÃO}

Inicialmente, as estruturas de códigos $6 l u 7$ e $5 r f 9$ foram abertas e alinhadas com o programa PyMol. Após o alinhamento, pode-se observar que a $\mathrm{M}^{\mathrm{PRO}}$ do SARS-CoV-2 apresenta dois sítios importantes de inibição, um aonde se liga o derivado de leucinamida, Figura 2 (A) e, outro de ligação ao derivado de pirazol,
Figura 2 (B). A partir destas informações cristalográficas iniciais e, partindo-se para as simulações por docagem molecular, se as moléculas utilizadas neste trabalho interagirem mais fortemente ou fracamente com estes sítios de ligação, do que os próprios ligantes cristalográficos, resultados poderão sugerir maiores ou menores atividades inibitórias.

Figura 2: Sobreposição das estruturas de códigos $\mathrm{PDB}, 6 \mathrm{lu} 7$ e 5rf9, com seus respectivos inibidores (A) derivado de leucinamida e (B) derivado de pirazol, com a região para docagem molecular, em destaque, envolvendo os dois sítios.

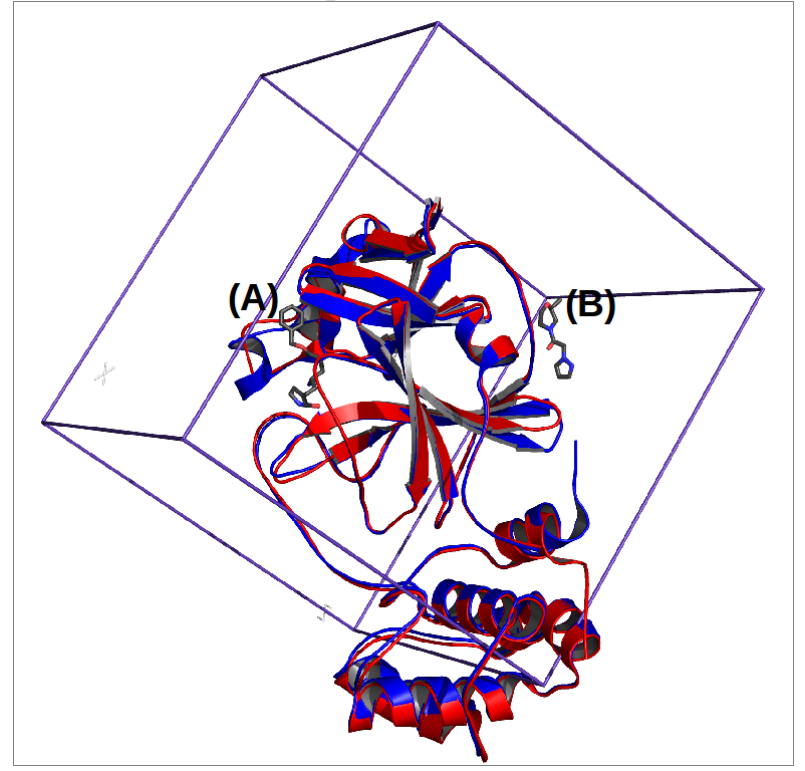

Após a predição dos estados de protonação em pH 7.4 com o programa MARVINSKETCH, a hidroxicloroquina e a

cloroquina ficaram carregados, positivamente, Figura 3, enquanto os outros ligantes, mantiveram-se neutros.

Figura 3: Estado de protonação dos ligantes após o tratamento com o programa MARVINSKETCH.

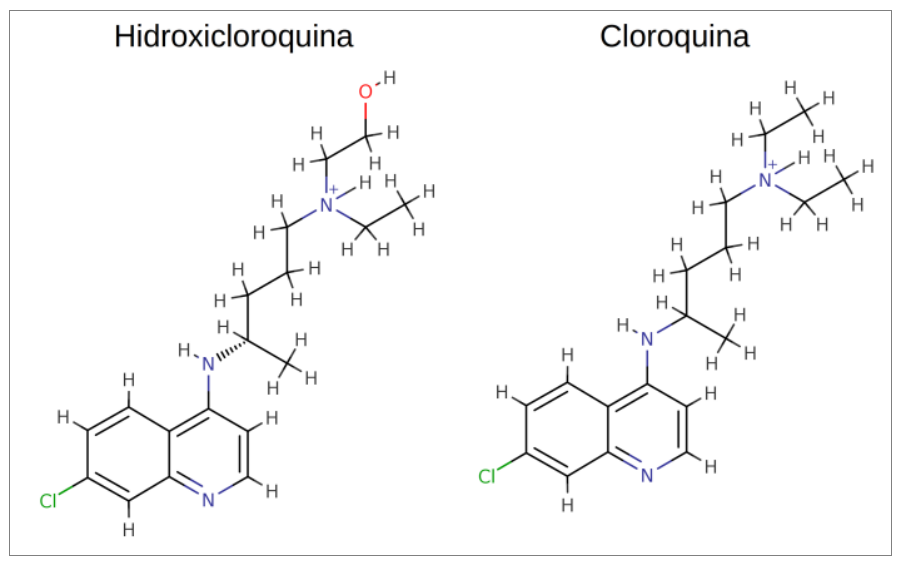


Posteriormente ao estudo do estado de protonação em $\mathrm{pH}$ fisiológico, os sistemas (receptor + ligantes) foram submetidos às simulações por docagem molecular.

Ao analisar os resultados de interação das moléculas com a $\mathrm{M}^{\mathrm{PRO}}$ do SARS-CoV-2, notou-se que todas, exceto o derivado de pirazol (fato esperado já que seu sítio de ligação é diferente), se ligaram no mesmo sítio de ligação do derivado de leucinamida, Figura 4. É importante destacar que as moléculas de AZT, vitamina $\mathrm{D}$, cloroquina e hidroxicloroquina se ligaram na mesma região do sítio ativo da enzima $\mathrm{M}^{\mathrm{PRO}}$ do coronavírus, indicando que esses compostos podem ter ação anti-viral. Isso é corroborado com testes clínicos realizados recentemente, onde estas mesmas moléculas foram usadas no tratamento de pacientes graves da COVID-19, entretanto foram observados graves efeitos colaterais (JUURLINK, 2020; GAUTRET et al., 2020; TOURET et al., 2020). Já para a vitamina $\mathrm{D}$, estudos recentes não publicados mostraram que ela pode ter um papel importante para o tratamento da doença, uma vez que pacientes com essa síndrome apresentaram alta deficiência desta vitamina. Vale ressaltar a relevância da vitamina $\mathrm{D}$, no organismo, como reguladora do sistema imune (HANEL et al, 2020).

Figura 4: Sobreposição de todos os resultados de docagem molecular com a $\mathrm{M}^{\mathrm{PRO}}$ do SARS-CoV-2.

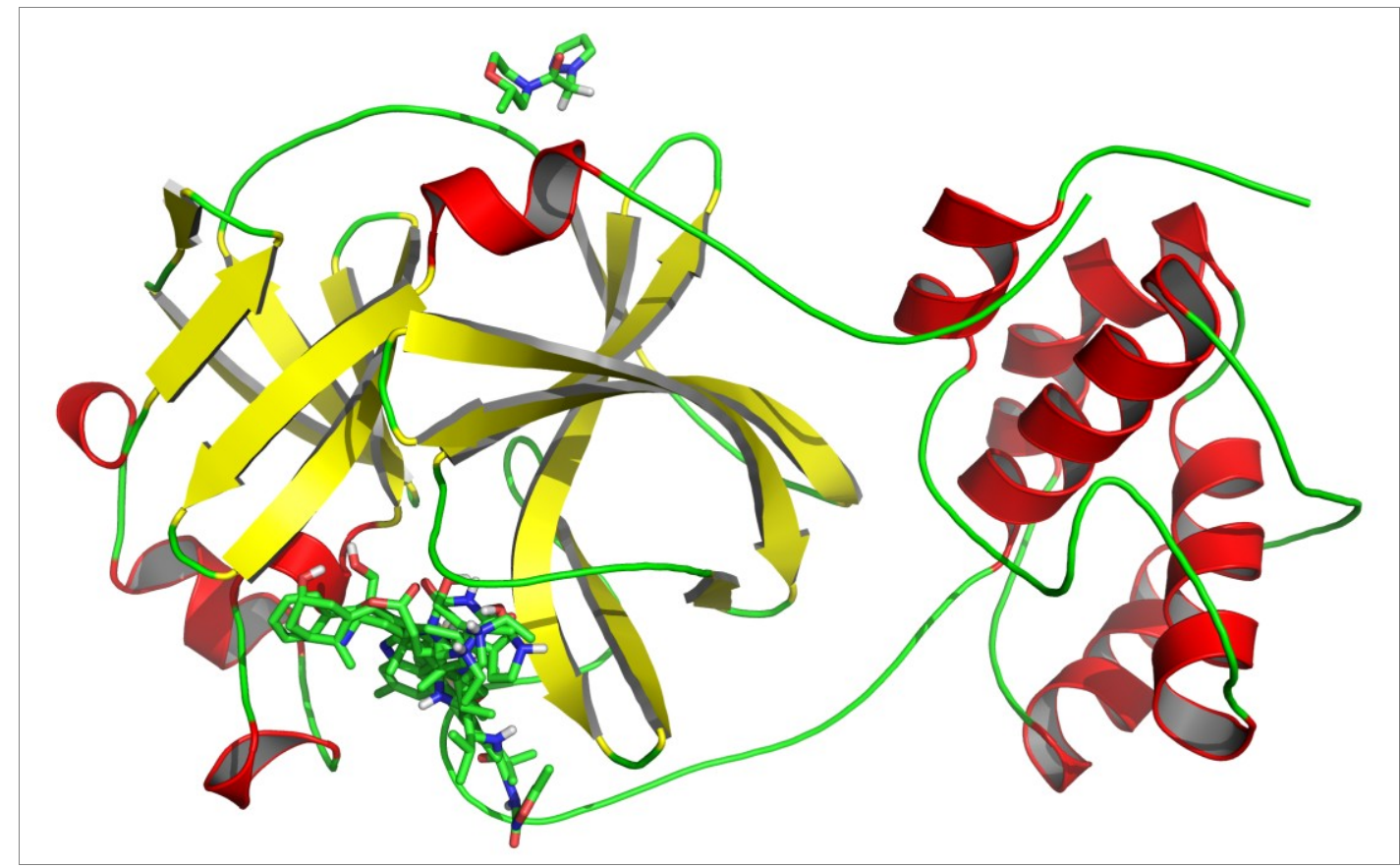

Para o monitoramento da afinidade de interação entre os ligantes e a $\mathrm{M}^{\mathrm{PRO}}$ do SARS-CoV-2, foram extraídas as energias livres de interação e construído um gráfico de $\mathrm{DG}_{\text {interação }}$ versus ligantes, Figura 5, mostrando que, o derivado de leucinamida se ligou mais fortemente (energia de $-7,7$ $\mathrm{kcal} / \mathrm{mol}$ ), enquanto o derivado de pirazol mais fracamente (energia de $-3,8 \mathrm{kcal} / \mathrm{mol}$ ). Ainda, em nível comparativo com o derivado de leucinamida, é importante destacar que a vitamida $\mathrm{D}$ teve a segunda melhor energia de interação $(-6,9 \mathrm{kcal} / \mathrm{mol})$, seguido pelo AZT $(-6,7 \mathrm{kcal} / \mathrm{mol})$, 
hidroxicloroquina $(-6,3 \mathrm{kcal} / \mathrm{mol})$ e a cloroquina $(-6,0 \mathrm{kcal} / \mathrm{mol})$, sugerindo que a vitamina $\mathrm{D}$ pode ter efeito promissor para o tratamento da COVID-19. É bom enfatizar que a vitamina $\mathrm{D}$ pode ser obtida a partir da exposição à radiação UVB proveniente dos raios solares e/ou a partir de suplementos alimentares.

Figura 5: Energia livre de interação versus ligantes.

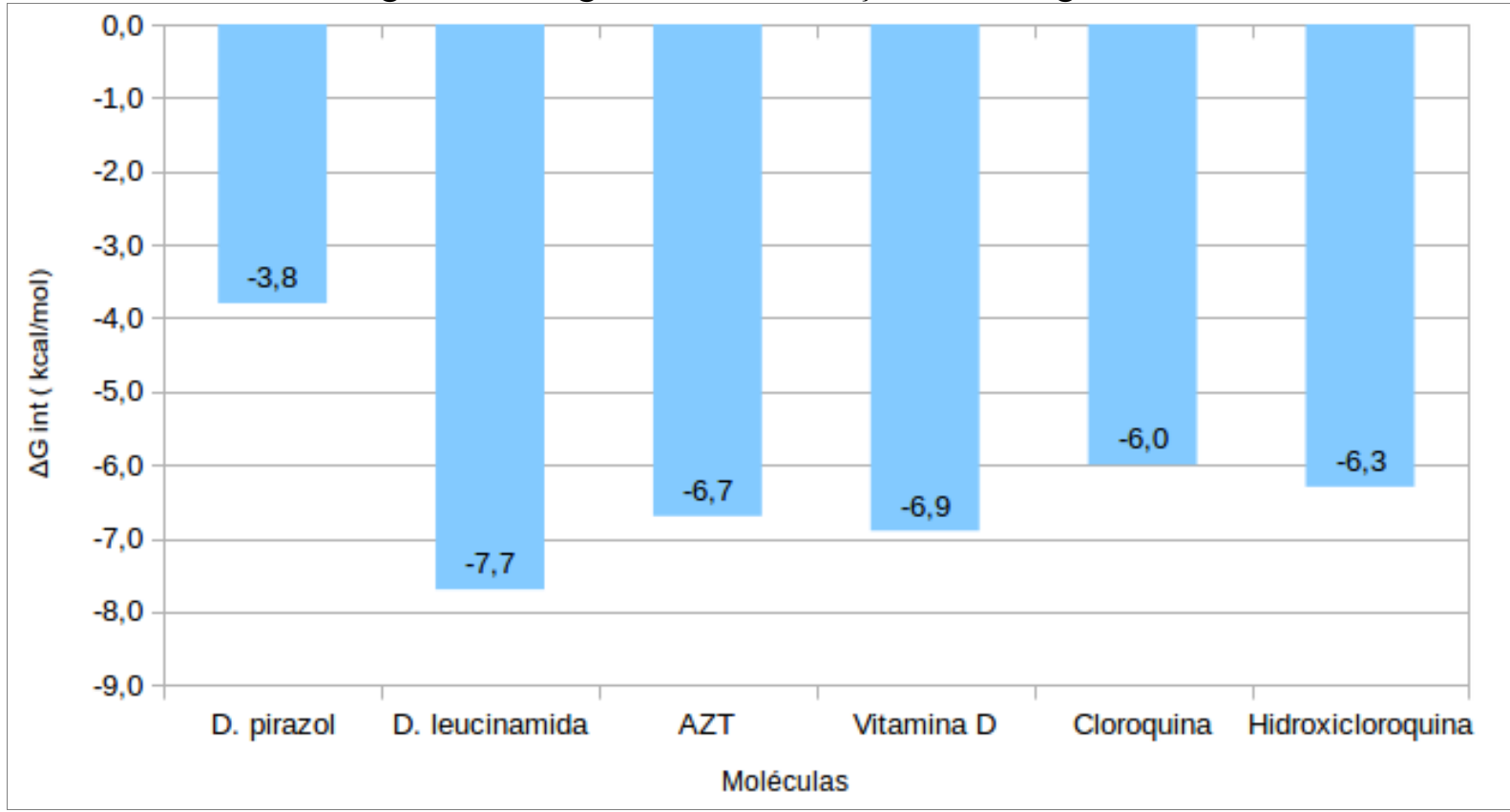

Para melhor visualização dos tipos de interações e dos principais aminoácidos que estão em contato com a $\mathrm{M}^{\mathrm{PRO}}$, a Figura 6 mostra o diagrama 2D das interações por docagem molecular. A partir da Figura 6, pode-se observar que todas as moléculas, exceto a cloroquina, interagiram com a Cys 145 via ligações hidrogênio e Pi-Alquil, sugerindo uma possível inativação da $\mathrm{M}^{\mathrm{PRO}}$. Este dado corrobora a literatura, onde o resíduo Cys145 é um dos aminoácidos catalíticos da $\mathrm{M}^{\mathrm{PRO}}$ do SARS-CoV-2
(ZHANG et al., 2020). Particularmente, a vitamina $D$ faz contatos com a Cys 145 (predominantemente por empilhamento $\mathrm{Pi}$ Alquil), a qual fica retida fortemente no sítio ativo, através de interação por ligação hidrogênio com o aminoácido Thr26. Além disso, observa-se vários contatos apolares, com o sítio ativo enzimático, se traduzindo na segunda melhor energia de afinidade, tendo em vista que as contribuições de van Der Waals, são tão importantes quanto as eletrostáticas. 
Figura 6: Visualização 2D dos presentes compostos e aminoácidos da protease de maior interação.

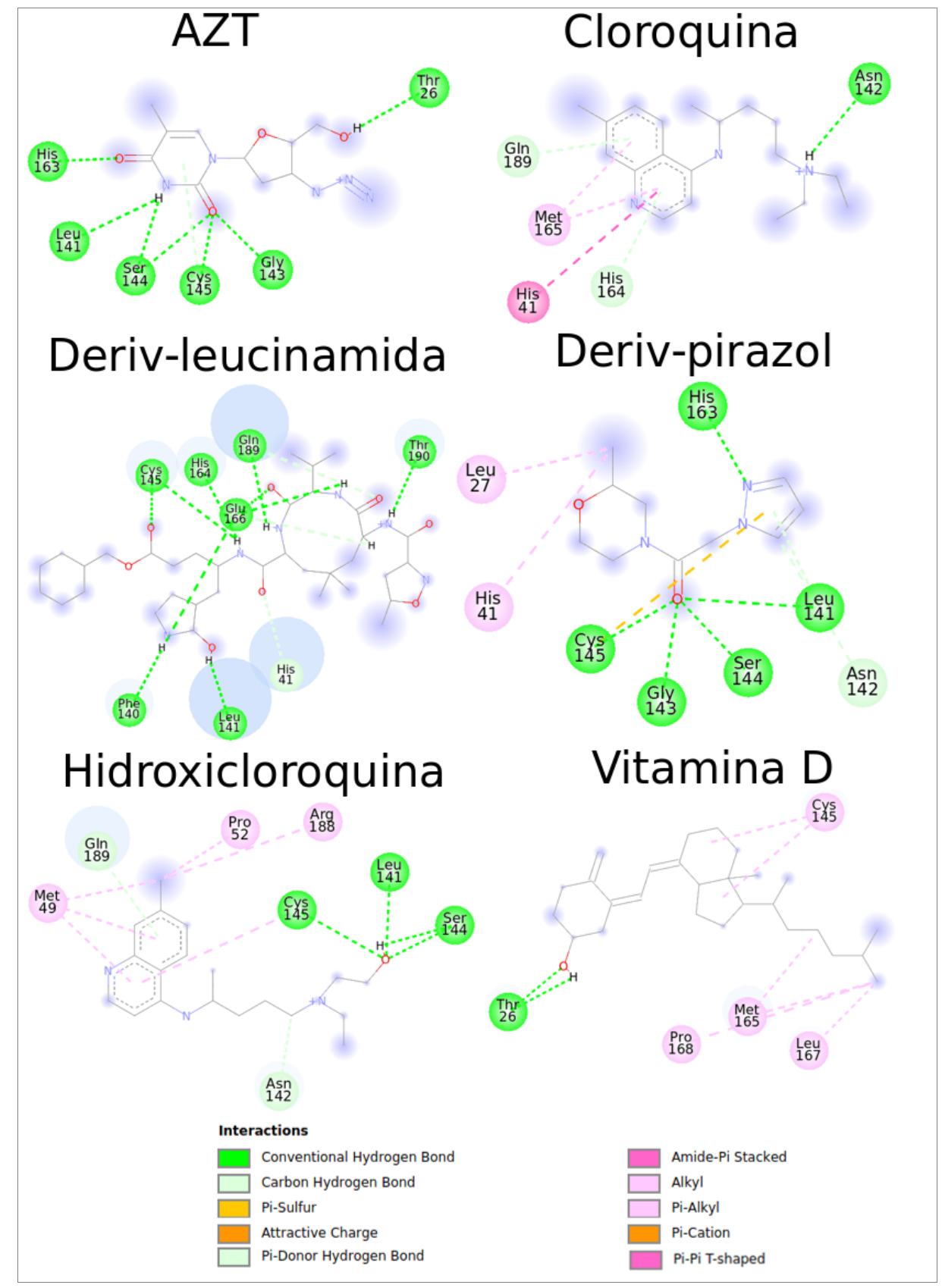

\section{CONCLUSÕES}

No presente trabalho, o método de docagem molecular foi utilizado para estudar algumas moléculas promissoras no tratamento da doença COVID-19 via inibição da enzima $\mathrm{M}^{\mathrm{PRO}}$, a protease principal do SARS-CoV-2. A partir dos resultados de docagem molecular, concluise que os ligantes que se ligam mais fortemente a $\mathrm{M}^{\mathrm{PRO}}$ do coronavírus, depois do derivado de leucinamida, foram a vitamina $\mathrm{D}$ e o AZT. Portanto, a vitamina D, que é uma molécula praticamente atóxica (até $100 \mathrm{ng} / \mathrm{mL}$ no sangue) pode ser utilizada para o tratamento da COVID-19. É importante destacar que, apesar das outras moléculas também apresentarem energias de interações razoáveis, estudos clínicos ainda precisam ser realizados, em razão de seus efeitos colaterais e de sua toxidez aos mamíferos. 


\section{AGRADECIMENTOS}

Os autores agradecem ao EDITAL PRPPG $N^{\circ} 10 / 2019$ do IFES - Programa Pesquisador de Produtividade (PPP), pelas horas disponibilizadas para realização de pesquisa, a FAPES / Editais 006/2014 (processo $\mathrm{n}^{\circ}$ 67648479/2014) e 03/2020 (processo EDocs $\mathrm{n}^{\circ}$ 2020-WMT5F) e a FAPESP (processo $\mathrm{n}^{0}$ 2018/19844-8) pelo suporte financeiro fundamental à aquisição dos computadores onde foram realizadas as simulações.

\section{REFERÊNCIAS}

ANVISA. AGÊNCIA NACIONAL DE VIGILÂNCIA SANITÁRIA - Capturado de [http://portal.anvisa.gov.br/] em 27 de abril de 2020.

BEARD, J. A.; BEARDEN, A.; STRIKER, R. Vitamin D and the anti-viral state. J Clin Virol, 50(3): 194-200, 2011.

COLSON, P.; ROLAIN, J. M.; LAGIER, J. C.; BROUQUI, P.; RAOULT, D. Chloroquine and hydroxychloroquine as available weapons to fight COVID-19. Int $\mathbf{J}$ Antimicrob Agents, 2020.

COLSON, P.; ROLAIN, J. M.; RAOULT D. Chloroquine for the 2019 novel coronavirus SARS-CoV-2. Int J Antimicrob Agents, 2020.

CORTEGIANI, A.; INGOGLIA, G.; IPPOLITO, M.; GIARRATANO, A.; EINAV, S. A systematic review on the efficacy and safety of chloroquine for the treatment of COVID-19. Journal of Critical Care, 2020.

DA SILVA, A. W. S., VRANKEN, W. F. (2012). ACPYPE-AnteChamber PYthon Parser interfacE. Biomed Central Res Notes, 5(1):367, 2012.

GAUTRET, P.; LAGIERA, J.C.; PAROLAA, P.; HOANGA, V.T.;
MEDDEBA, L.; MAILHE, M.; DOUDIER, B.; COURJON, J.; GIORDANENGO, V.; VIEIRA, V. E.; DUPONT, H. T.; HONORÉ, S.; COLSON, P.; CHABRIÈRE, E.; LA SCOLA, B.; ROLAIN, J. M.; BROUQUI, P.; RAOULT, D. Hydroxychloroquine and azithromycin as a treatment of COVID-19: results of an open label non-randomized clinical trial. Int. J. Antimicrob. Agents, In press https://doi.org/10.1016/j.ijantimicag.2020.1 05949

HANEL, A.; MALMBERG, H. R.; CARLBERG, C. Genome-wide effects of chromatin on vitamin D signaling. J Mol Endocrinol. Mar 1. pii: JME-19-0246.R3.

HASSINEN， T; PERÄKYLÄ， M. New energy terms for reduced protein models implemented in an off-lattice force field. $\mathbf{J}$ Comput Chem, 22(12):1229-1242, 2001.

JUURLINK, D. N. Safety considerations with chloroquine, hydroxychloroquine and azithromycin in the management of SARSCoV-2 infection. CMAJ, Preprint, 2020.

MAZUROV, D.; ILINSKAYA, A.; HEIDECKER, G.; LLOYD, P.; DERSE, D. Quantitative Comparison of HTLV-1 and HIV-1 Cell-to-Cell Infection with New Replication Dependent Vectors, PLoS Pathog, 6(2), 2010.

MORRIS, G. M.; HUEY, R.; LINDSTROM, W.; SANNER, M. F.; BELEW, R. K.; GOODSELL, D. S.; OLSON, A. J. AutoDock4 and AutoDockTools4: auto-mated docking with selective receptor flexibility. J ComputChem, 30(16):2785-2791, 2009.

PIETRALONGA, T. C., GONÇALVES, A. S. GONÇALVES, S. Q. B., FRANÇA, T. C. C. Estudo computacional de reativadores da acetilcolinesterase inibida pelo pesticida agrícola fenamifós. Ifes Ciência. Espirito Santo, v. 1, n. 2, 2015. 
ROWEN, R. J.; ROBINS, H. A Plausible "Penny" Costing Effective Treatment for Corona Virus - Ozone Therapy. J Infect Dis Epidemiol, 6:113, 2020.

SANTÉ PUBLIQUE FRANCE. Infection au nouveau Coronavirus (SARS-CoV-2), COVID-19, France et Monde [https://www.santepubliquefrance.fr/maladie s-et-traumatismes/maladies-et-infectionsrespiratoires/infection-acoronavirus/articles/infection-au-nouveaucoronavirus-sars-cov-2-covid-19-france-etmonde].

SHIH, J. H.; CHEN, C. L. Molecular dynamics simulation of bisphenol A polycarbonate. Macromolecules, 28(13):4509-4515, 1995.

STEWART, J. J. Optimization of parameters for semiempirical methods $\mathrm{V}$ : Modification of NDDO approximations and application to 70 elements. J Mol Model, v.13, p.1173-1213, 2007.

TOURET, F., DE LAMBALLERIE, X. Of chloroquine and COVID-19, Antivir. Res. $177,104762,2020$

TROTT, O; OLSON, A. J. AutoDock Vina: improving the speed and accuracy of docking with a new scoring function, efficient optimization and multithreading. J

Comput Chem. 31(2):455-461, 2010.

WORLD HEALTH ORGANIZATION (WHO). Coronavirus disease (COVID2019) situation reports, 2020.

WU, Z.; MCGOOGAN, JM. Characteristics of and important lessons from the coronavirus disease 2019 (COVID-19) outbreak in China: summary of a report of 72314 cases from the Chinese Center for Disease Control and Prevention. JAMA, 2020.

XIANG, F.; WANG, X.; HE, X.; PENG, Z.; YANG, B.; ZHANG, J.; ZHOU, Q.; YE, H.; MA, Y.; LI, H.; WEI, X.; CAI, P.; MA, W. L. Antibody Detection and Dynamic Characteristics in Patients with COVID-19. Clin Infect Dis., 2020.

ZHANG, L.; LIN, D.; SUN, X.; CURTH, U. et al. Crystal structure of SARS-CoV-2 main protease provides a basis for design of improved $\alpha$-ketoamide inhibitors. Science 10.1126/science.abb3405 (2020). 